\section{Just a crush? Contamination of archaeological samples by different grinding media}

\author{
Rachel E. ten Bruggencate, ${ }^{1}$ Mostafa \\ Fayek, ${ }^{2}$ S. Brooke Milne, ${ }^{1}$ Robert W. \\ Park, $^{3}$ Douglas R. Stenton ${ }^{3}$ \\ ${ }^{1}$ Centre for Earth Observation Science, \\ University of Manitoba; ${ }^{2}$ Department of \\ Geological Sciences, University of \\ Manitoba; ${ }^{3}$ Department of Anthropology, \\ University of Waterloo, Canada
}

\section{Abstract}

A chert cobble from an archaeological quarry on southern Baffin Island, Canada, was divided and crushed using five different methods: i) agate mortar and pestle, ii) stainless steel shatterbox, iii) tungsten carbide shatterbox, iv) alumina ceramic shatterbox, and v) zirconia ceramic shatterbox. Powders produced by each method were submitted for acid digestion and analysis by inductively coupled plasma mass spectrometry. The trace element results indicate that different crushing media can contribute significant trace element contamination to chert during the grinding process. These results demonstrate the need for an informed approach to the selection of sample preparation methods when submitting archaeological samples for solution or pellet based geochemical analysis.

\section{Introduction}

Raw material provenance research has become a standard approach for the analysis of lithic assemblages. Many archaeologists undertaking provenance studies work directly with the geochemical equipment used to provide characteristic trace element or isotopic data, or collaborate closely with those who do. However, archaeologists without direct access to suitable equipment also have the option of submitting samples to commercial geochemical laboratories, where analysis is undertaken and results are returned without the archaeologist's direct involvement for a fee.

Researchers submitting samples to commercial labs are required to select appropriate sample preparation and analysis protocols from catalogues according to the material that is being submitted and the type of required analysis. The suitability of different analytic techniques for lithic provenance research has been the subject of numerous publications (e.g., Longoni et al., 1998; Janssens et al., 2000;
Smith and Clark, 2004; Glascock et al., 2007; Hull et al., 2008; 2014; Milne et al., 2009, 2011, Resano et al., 2010; ten Bruggencate et al., 2013). However, the effect of different preparation protocols on sample chemistry has received less attention from archaeologists, in spite of its significance for accurate data acquisition (although, see: Boulanger et al., 2013).

Crushing or powdering samples prior to inductively coupled plasma mass spectrometry (ICP-MS) or X-ray fluorescence spectroscopy, in particular, has the potential to introduce contaminants to lithic raw material and artifact samples, skewing the results of geochemical provenance studies. Hickson and Juras (1986), Iwansson and Landström (2000), and Takamasa and Nakai (2009) have demonstrated that a variety of contaminants can be introduced by different materials during hand and mechanical crushing of quartz sand standards and solid geological samples. Here we describe a study aimed at understanding the effects of different crushing media on the chemistry of raw chert samples of unknown composition from an archaeologically exploited quarry on southern Baffin Island (Figure 1).

\section{Materials and Methods}

\section{The LbDt-1 quarry}

The sample used in this study was obtained from the quarry designated as LbDt-1, located in the interior of southern Baffin Island on the Hone River, approximately $115 \mathrm{~km}$ WNW of Iqaluit, Nunavut, Canada (Figure 1). The site consists of occupation and lithic reduction features distributed over an upper and lower terrace along the river. Chert is available at both elevations on site - weathering out of degrading limestone boulders on the upper terrace, and as a component of limestone strata outcropping on the lower terrace (Figure 2). Massive, dense chert debitage scatters located on the upper and lower terraces of the site suggest intensive precontact exploitation of lithic resources at LbDt-1. No clearly diagnostic artifacts were recovered at LbDt-1; however Palaeo-Eskimos are the only arctic peoples known to have extensively utilized chert as a raw material for chipped stone tool manufacture, minimally placing occupation of the site within the Palaeo-Eskimo period (roughly 4500-950 years before present; Milne, 2014).

\section{Chert samples}

The samples analyzed in this study derive from a large chert nodule, and were obtained using a geological hammer from the limestone outcrop on the lower terrace of LbDt-1. This cobble was selected for analysis due to its
Correspondence: Rachel E. ten Bruggencate, Center for Earth Observation Science, University of Manitoba, 125 Dysart Road, R3T 2N2 Winnipeg, MB, Canada.

Tel. +1.204.4746328 - Fax: +1.204.2721532.

E-mail: tenbrugg@cc.umanitoba.ca

Key words: chert, inductively coupled plasma mass spectrometry, contamination, sample preparation, provenance.

Contributions: RET, MF, data collecting and analyzing; SBM, MF, fieldwork to collect sample; RET, manuscript writing; MF, SBM, RWP, DRS, manuscript review.

Conflict of interests: the authors declare no potential conflict of interest.

Funding: this work was supported by Social Sciences and Humanities Research Council Insight Grant \#435-2012-1176; Canada Foundation for Innovation John R. Evans Leaders Fund \#25071; Manitoba Research and Innovation Fund, Manitoba Heritage Grants Program \#12FH145; the Polar Continental Shelf Project, Natural Resources Canada \#64713, \#61712; and the Northern Scientific Training Program, Aboriginal Affairs and Northern Development Canada.

This work is licensed under a Creative Commons Attribution 3.0 License (by-nc 3.0).

(C) Copyright R.E. ten Bruggencate et al., 2014 Licensee PAGEPress, Italy

Open Journal of Archaeometry 2014; 2:5606 doi:10.4081/arc.2014.5606

homogenous appearance, containing relatively few macroscopically observable mineral or fossil inclusions compared to other chert samples from this site (Figure 3).

The cobble was sectioned into four $\sim 1 \mathrm{~cm}$ thick slices using a diamond wafering blade and IsoMet 1000 saw (Beuhler, Lake Bluff, IL, USA). Cortex was removed from each slice, after which the slices were further sectioned into five chips, weighing roughly $2.5 \mathrm{~g}$ each, for a total of 20 samples. Chips were sonicated for 10 minutes in successive baths of distilled water, 95\% ethanol, and 200-proof anhydrous ethanol and allowed to dry. Each chip was reduced to roughly quarter-inch grade using an agate mortar and pestle. The agate mortar and pestle was wiped clean with distilled water, $95 \%$ ethanol, and 200-proof anhydrous ethanol between each sample. One crushed chip from each slice was selected for powdering through one of five methods: i) agate mortar and pestle, ii) stainless steel shatterbox, iii) tungsten carbide shatterbox, iv) alumina ceramic shatterbox, or v) zirconia ceramic shatterbox.

The agate mortar and pestle and all shatterboxes were wiped clean between each sample with distilled water, 95\% ethanol, and 200 - 
proof anhydrous ethanol. Shatterboxes were hand-agitated until samples were powdered. Powdered samples were removed to individual, labeled plastic bags and submitted to a commercial laboratory for acid digestion and ICPMS analysis. Twenty-five milligrams $(0.25 \mathrm{~g})$ of sample was digested first in hydrofluouric acid, followed by a nitric and perchloric acid mixture and heated to dryness. Dry samples were then dissolved using hydrocholoric and nitric acid and introduced into the ICP-MS.

\section{Results}

While some elemental concentrations do not appear to be affected by different sample preparation regimes, others appear to have been slightly to strongly influenced by different crushing media (Table 1; Figure 4). Samples ground with the agate mortar and pestle appear to have higher average concentrations of Zn (67.6 ppm), As (5.1 ppm), Y (0.3 ppm), Zr (10.0 ppm), Cu (130.1 ppm), Pb (4.28 ppm), and $\mathrm{U}(19.7 \mathrm{ppm})$ than those prepared by other media. Powdering in a zirconia ceramic shatterbox contributed $\mathrm{Cr}(10.7 \mathrm{ppm}), \mathrm{Mg}(0.04 \%)$, Hf (10.4 ppm), Zr (550.5 ppm), and Th (0.38 ppm) contamination to samples relative to other media. Significant W (157.3 ppm) and Co (104.1 ppm) contamination was introduced to the samples through powdering in tungsten carbide. Elevated Ta $(0.5 \mathrm{ppm})$ levels relative to samples crushed in other media were also observed in samples crushed using tungsten carbide. Powdering in the stainless steel shatterbox introduced $\mathrm{Al}(0.27 \%), \mathrm{Cr}(102.5 \mathrm{ppm})$, Mn (31.8 ppm), Fe (0.19\%), Ni (4.0 ppm), Mo $(0.9 \mathrm{ppm})$, and $\mathrm{La}(1.5 \mathrm{ppm})$ contamination relative to powdering in other media. Mean B concentrations for samples powdered in the alumina (23.0 ppm), tungsten carbide (22.0 ppm), zirconia (18.0 ppm), and stainless steel (21.5 ppm) shatterboxes are all slightly higher than that recorded for samples powdered using the agate mortar and pestle (14.3 ppm). However, the standard deviations associated with these measurements render this variation statistically insignificant.

\section{Discussion}

Some of the contamination introduced to chert samples by different crushing media was expected. Y, Pb, and U contamination by crushing in agate (Takamasa and Nakai, 2009), Zr contamination by crushing zirconia ceramic, $\mathrm{Co}, \mathrm{W}$, and Ta contamination by crushing in tungsten carbide (Thompson and Bankston,

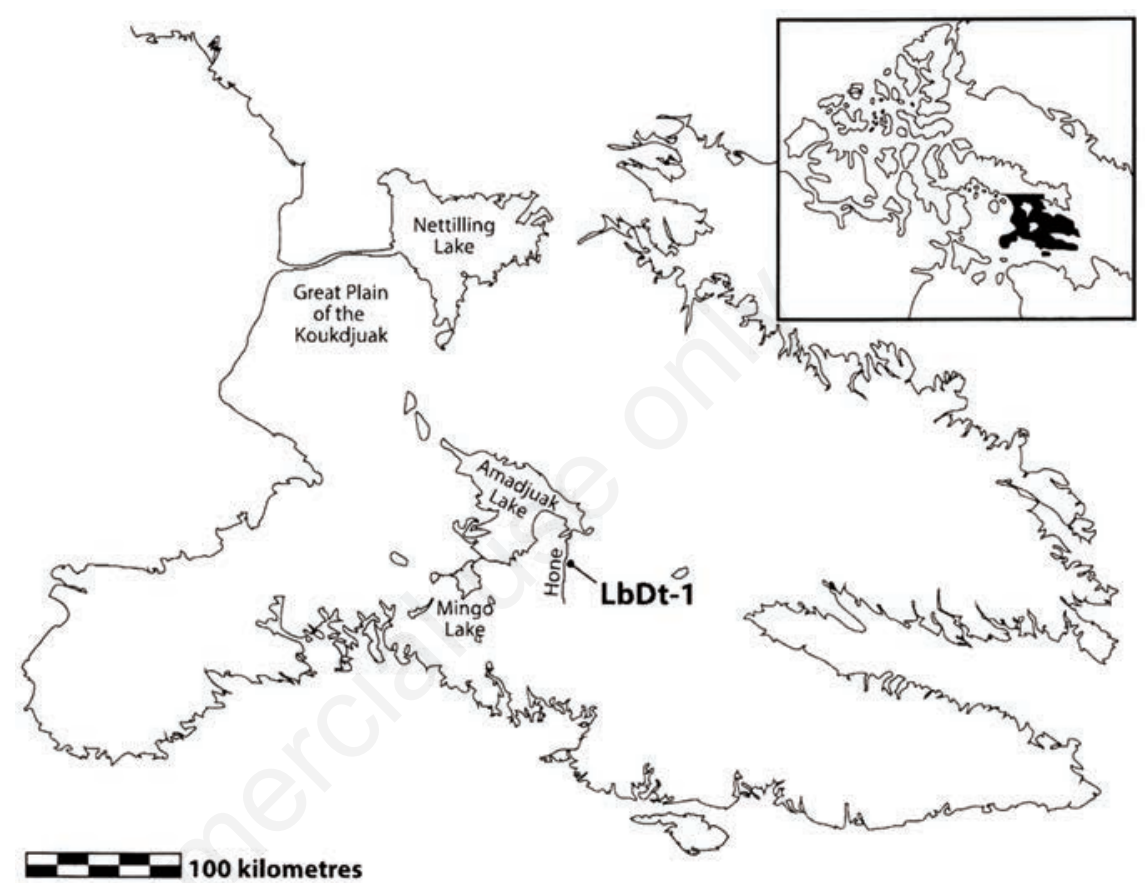

Figure 1. Map of southern Baffin Island, Nunavut, Canada, showing the location of the chert quarry, LbDt-1.

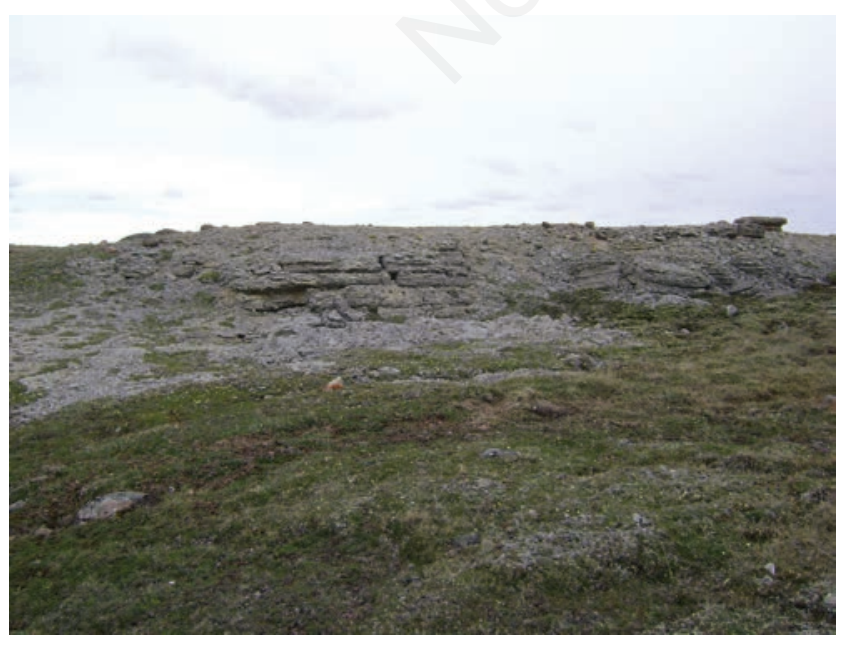

Figure 2. Photograph of the exposed chert/limestone strata and boulders quarried at LbDt-1.

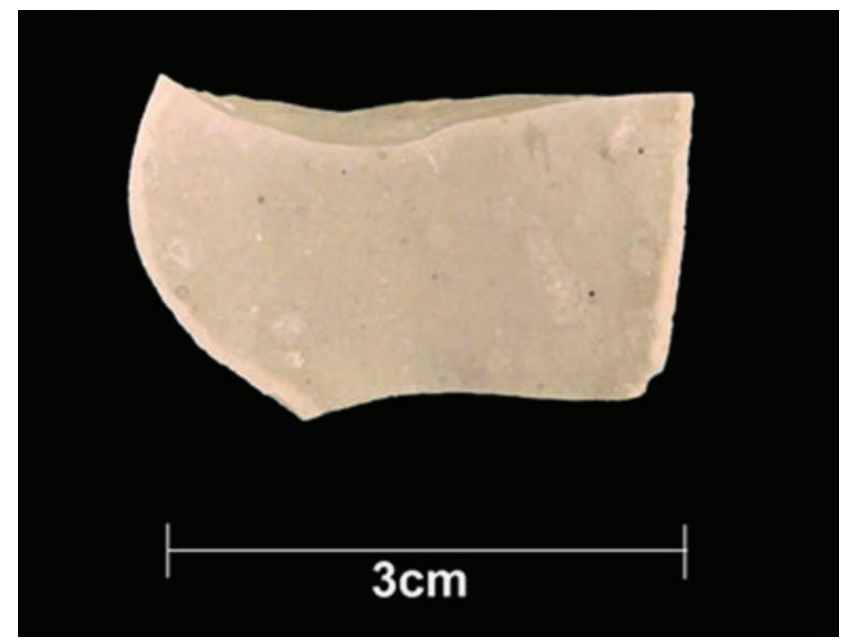

Figure 3. Section of sample CFB-1. 
Table 1. Mean solution inductively coupled plasma mass spectrometry results for four samples prepared by each medium with associated standard deviations.

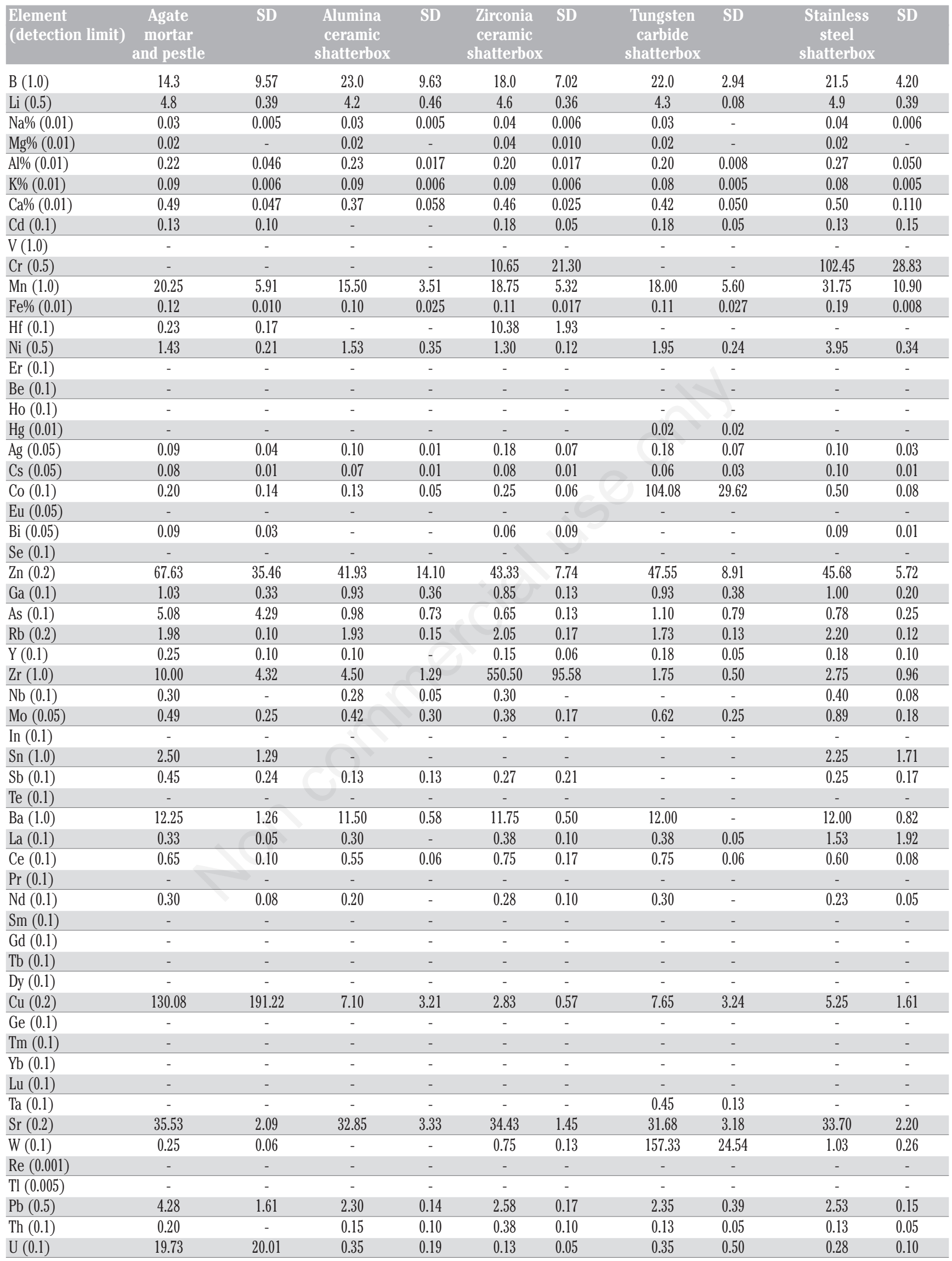

-, results below detection limits and standard deviations for means where all four samples returned statistically indistinguishable results. All results given in parts per million unless otherwise noted. 


\section{Discussion}

Some of the contamination introduced to chert samples by different crushing media was expected. $\mathrm{Y}, \mathrm{Pb}$, and $\mathrm{U}$ contamination by crushing in agate (Takamasa and Nakai, 2009), Zr contamination by crushing zirconia ceramic, $\mathrm{Co}, \mathrm{W}$, and Ta contamination by crushing in tungsten carbide (Thompson and Bankston, 1970, Roser et al., 1998), and $\mathrm{Al}, \mathrm{Fe}, \mathrm{Cr}$, and Mo contamination by crushing in stainless steel (Myers and Barnett, 1953; Hickson and Juras, 1986) are not surprising outcomes, as they are major elemental constituents of each material and/or were noted as introduced contaminants during previous studies. It is likely that $\mathrm{U}, \mathrm{Cu}$, $\mathrm{As}, \mathrm{Zn}$, and $\mathrm{Pb}$ contamination of samples by the agate mortar and pestle is also related to prior powdering of uranium- and sulphide-rich samples using this equipment, as it is stored in a laboratory where such samples are regularly prepared.

Introduction of $\mathrm{Cr}, \mathrm{Mg}, \mathrm{Hf}$, and Th by crushing in zirconia was unexpected. The lack of any significant trace element contamination in samples powdered in the alumina ceramic shatterbox was also surprising given previous research, which identified $\mathrm{Al}, \mathrm{Ba}, \mathrm{Cr}, \mathrm{Cs}, \mathrm{Cu}$, $\mathrm{Ga}, \mathrm{Fe}, \mathrm{W}, \mathrm{Pb}$, and $\mathrm{Zr}$ as potential contaminants resulting from crushing in this medium (Thompson and Blankston, 1970; Hickson and Juras, 1986; Takamasa and Nakai, 2009).

Finally, it is worth noting that many mean values reported in Table 1 are associated with high standard deviations - some equal to or exceeding the value of the mean. For low concentration analytes, this variability may be related to high instrumental error associated with quantifying elements at or near to ICPMS detection limits. For others, like B, Zn, and As, microscale chemical heterogeneity in the chert sample selected for this study may play a role. This variability may also be related to differential exposure to contaminants introduced to the shatterboxes or mortar and pestle by previously prepared samples. This is almost certainly the cause of the high standard deviation associated with the mean $\mathrm{Cu}$ value for samples crushed using agate, as individual sample $\mathrm{Cu}$ levels were observed to drop drastically from the first sample crushed (415 ppm) to the last (8.5 ppm).

\section{Conclusions}

Our results demonstrate that different crushing techniques have the potential to affect the chemistry of materials with low trace element concentrations, like chert, to a degree that could compromise a provenance study

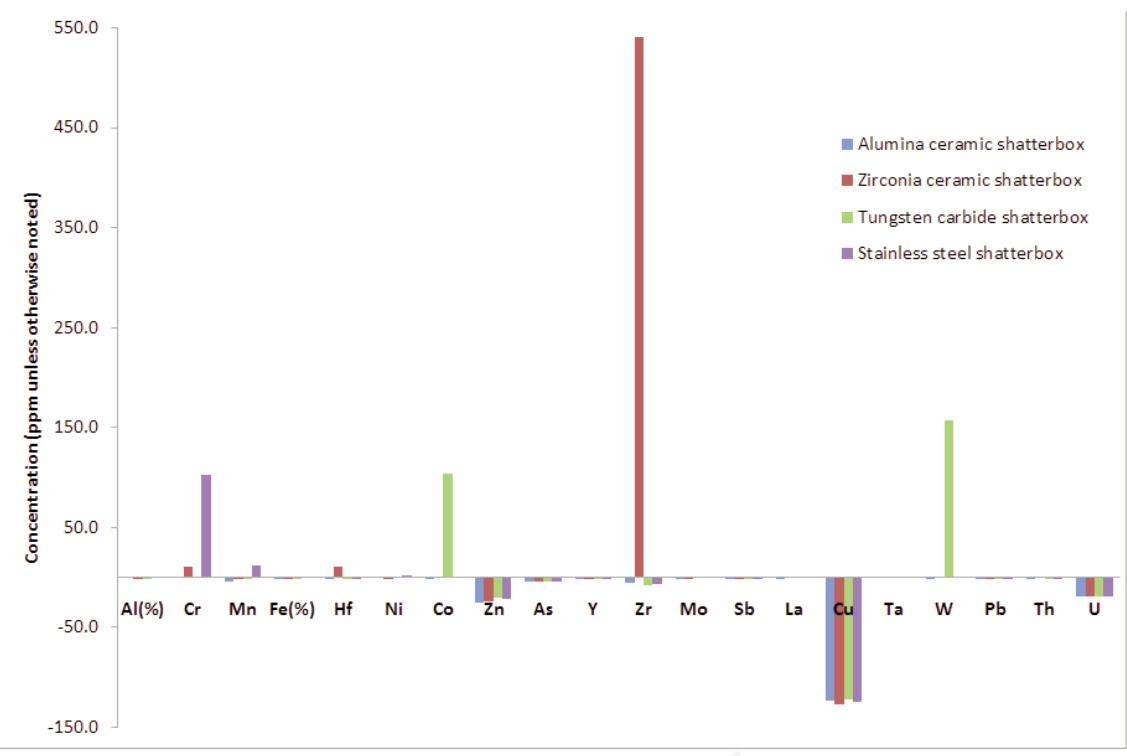

Figure 4. Bar graph showing mean abnormal elemental concentrations in samples crushed in other media relative to samples crushed in agate mortar and pestle. All results in parts per million (ppm) unless otherwise noted.

based on solution or pellet analysis. Care must be taken with the selection of a crushing method that does not interfere with elements of potential utility for distinguishing between materials from different archaeologically exploited sources. Of the five crushing techniques, powdering in an alumina shatterbox appears to produce data least affected by contamination. As noted, this comes as a surprise, given previous studies (Thompson and Blankston, 1970; Hickson and Juras, 1986; Takamasa and Nakai, 2009), which note crushing in alumina ceramics as a likely source of a number of trace element contaminants. Therefore, caution must be taken in selecting an alumina crush for low-concentration samples, even in light of the above discussion. We also note unexpected contaminants introduced by agate. This contradicts the results of other studies (Myers and Barnett, 1953; Barnett et al., 1955; Thompson and Blankston, 1970; Hickson and Juras, 1986), which treat crushing in agate as either a completely or nearly contamination-neutral process. As stated, it is likely that previous samples crushed using this equipment either caused or exacerbated this contamination. Even with thorough cleaning, otherwise low contaminant crushing equipment like agate should only be used if it is known that contact with materials containing trace elements of possible interest did not occur in the past.

Laboratory technicians at commercial facilities may be aware of potential sources of sample contamination during crushing; however, the onus is placed on the researcher ordering the sample preparation and subsequent analysis to select protocols that will not interfere with analytes of potential interest to their work. It is our hope that this study clearly demonstrates the need for archaeologists to be cautious when selecting sample crushing packages or grinding samples in-house prior to provenance research based on solution or pellet trace element analysis.

\section{References}

Barnett PR, Huleatt WP, Myers AT, 1955. Spectrographic determination of contamination of rock samples after grinding with alumina ceramic. Am J Sci 253:121-4.

Boulanger MT, Fehrenbach SS, Glascock MD, 2013. Experimental evaluation of sampleextraction methods and the potential for contamination in ceramic specimens. Archaeometry 55:880-92.

Glascock MD, Speakman RJ, Neff H, 2007. Archaeometry at the University of Missouri Research Reactor and the provenance of obsidian artefacts in North America. Archaeometry 49:343-57.

Hickson CJ, Juras SJ, 1986. Sample contamination by grinding. Can Mineral 24:585-9.

Hull S, Fayek M, Mathien FJ, Roberts H, 2014. Turquoise trade of the Ancestral Puebloan: Chaco and beyond. J Archaeol Sci 45;18795.

Hull S, Fayek M, Mathien FJ, Shelley P, Durand $\mathrm{KR}, 2008$. A new approach to determining 
the geological provenance of turquoise artifacts using hydrogen and copper stable isotopes. J Archaeol Sci 35:1355-69.

Iwansson K, Landström 0, 2000. Contamination of rock samples by laboratory grinding mills. J Radioanal Nucl Ch 244:609-14.

Janssens K, Vittiglio G, Deraedt I, Aerts A, Vekemans B, Vincze L, Wei F, De Ryck I, Schalm 0, Adams F, Rindby A, Knöchel A, Simionovici A, Snigirev A, 2000. Use of microscopic XRF for non-destructive analysis in art and archaeometry. X-ray Spectrom 29:73-91.

Longoni A, Fiorini C, Leutenegger P, Sciuti S, Fronterotta G, Strüder L, Lechner P, 1998. A portable XRF spectrometer for nondestructive analyses in archaeometry. Nucl Instrum Meth A 409:407-9.

Milne SB, 2014 Chert sourcing and PalaeoEskimo stone tool technology. Government of Nunavut, Department of Culture and Heritage (CA) Publ., Iqaluit (NU), Canada.

Milne SB, Hamilton A, Fayek M, 2009. Combining visual and geochemical analyses to source chert on southern Baffin Island, Arctic Canada. Geoarchaeology 24:429-49.

Milne SB, Park RW, Hamilton AC, Fayek M, 2011. Chert sourcing and Palaeo-Eskimo raw material use in the interior of southern Baffin Island, Arctic Canada. Can J Archaeol 35:117-42.

Myers AT, Barnett PR, 1953. Contamination of rock samples during grinding as determined spectrographically. Am J Sci 251:814-30.

Resano M, García Ruiz E, Vanhaecke F, 2010. Laser ablation-inductively coupled plasma mass spectrometry in archaeometric research. Mass Spectrom Rev 29:859-83.

Roser BP, Sawada Y, Kabeto K, 1998. Crushing performance and contamination trials of a tungsten carbide ring mill compared to agate grinding. Geosci. Rept. Shimane Univ. 17:1-11.

Smith GD, Clark RJ, 2004. Raman microscopy in archaeological science. J Archaeol Sci 31:137-60.

Takamasa A, Nakai SI, 2009. Contamination introduced during rock sample powdering: effects from different mill materials on trace element contamination. Geochem J 43:389-94.

ten Bruggencate RE, Fayek M, Brownlee K, Milne SB, Hamilton S, 2013. A combined visual-geochemical approach to establishing provenance for pegmatite quartz artifacts. J Archaeol Sci 40:2702-12.

Thompson G, Bankston DC, 1970. Sample contamination from grinding and sieving determined by emission spectrometry. Appl Spectrosc 24:210-9. 